\title{
On Adaptation in Military Operations: Tinkering and Bottom-Up Perspectives
}

\author{
JOBBÁGY Zoltán ${ }^{1}$
}

\begin{abstract}
A biological perspective has much to offer for a better understanding of military operations. Biological evolution and military operations feature perpetual novelty and conditions far from equilibrium featuring dynamics that demand continuous adaptation. The author suggests that comprehending military operations in an evo- lutionary framework requires a shift from mechanics and engineering to biology and adaptation. Thus the emphasis moves from statics to dynamics, from time-free to time-prone reality, from determinism to probability and chance, and from uni-formity to variation and diversity, with all the consequences.
\end{abstract}

\section{Introduction}

A biological perspective on human behaviour has much to offer for a better understanding of the relationship between co-operation and conflict. Regardless whether one sees war and military operations through the eyes of Clausewitz, approach it as a complex adaptive sys- tem, or examine it along attributes that display similarities with biological evolution, there are timeless and innate characteristics. It is not difficult to conclude that both biological evolution and military operations are intrinsically complex, and primordial violence is at the heart of both. [1]

Military operations indeed can be understood as a complex adaptive system in which the system properties emerge from the interactions of the many components at lower levels. The abundance of dispersed interactions in military operations indicates a mechanism that often lacks global control, but feeds from cross-cutting hierarchical setup. Similar to biolog- ical evolution, military operations also feature perpetual novelty and far from equilibrium dynamics that demand continual adaptation. Their composition changes constantly and the interaction of the belligerents means that there is a multiplicity of feedback mechanisms that affect the further dynamics by constantly changing attributes. [2]

Military operations and biological evolution are as much about selection as about trans- formation with the consequence that adaptation appears to be a central feature. Adaptation stands for the importance of not only how to respond to perturbations properly, but also how to maintain the capacity to respond actively. [3] Evolution and military operations are full of ramifications and divergences that come as a result of constant interactions and changing environmental conditions resulting in various and often unexpected events. [4]

1 National University of Public Service, Budapest, Hungary, The Faculty of Military Sciences and Officer Training, email: Jobbagy.Zoltan@uni-nke.hu 


\section{Biological Evolution and Civilized Warfare}

In book eight, chapter three of On War, Clausewitz, by detailing the interdependence of the elements of war, made it clear that scientific analysis based on logic and mathematics is of little help. War is an art and as such requires certain skills to discriminate among an infinite multitude of objects and relations to find out which is the most important and decisive. This sort of judgment stands in sharp contrast to a strict logical deduction and requires intuitive comparison. Remote and unimportant things and indirect relations must be set aside in order to discover the more immediate and important ones. [5]

Clausewitz as a theorist was aware of the fact that war has a non-quantitative and non- predictive character, which makes it impossible for fully fledged empirical or hard sciences to offer suitable descriptions, explanations or models. War exhibits structural unpredictabil- ity in which the distribution or dispersal of information suggests definite limits to what can be known at any given point in time. Given war's nature as outlined by Clausewitz, Watts argued that evolutionary biology may offer a better model for a scientific theory of war than most quantitative sciences. [6]

Darwin had neither intention nor interest in spending much time examining the nature of war. However, even he recognised in his book On the Origins of Species that genetic usur- pation and endemic warfare share similarities. In chapter three he drew an analogy between war, battle and natural selection and saw evolution as a "[b]attle within battle [that] must ever be recurring with varying success." This analogy made him conclude that "from the war of nature, from famine and death, the most exalted object which we are capable of conceiving, namely, the production of the higher animals, directly follows." Biological evolution was for him a "great and complex battle of life", which together with the "Law of Battle" for survival formed a recurrent pattern also in his second epic work The Decent of Man. [7]

In the preface to his book titled Adaptive Coloration in Animals published in 1957, Hugh Cott, another biologist, observed a striking similarity between the primeval struggle of the jungle and the refinements of civilized warfare and concluded that both have very much the same story to tell. In evolution and warfare there are results of an armament race and an in- vention race, which has led to a state of preparedness for offence and defence as complex as it is interesting. The methods employed in both are, according to him, mainly similar as shown by the evolution of speed, on land, in the air, and under water, by pursuer and pursued. Both can be characterized by the employment of stealth and surprise, of deception and ambush. There is a display of warning signals and of alluring baits, the elaboration of smokescreens, traps, nets, parachutes, of electrocution and booby-traps. In both there is evidence for the adoption of fossorial and nocturnal habits, the development of poison, and of deadly appara- tus in the form of fangs or stings or arrows for its injection into the bodies of enemies or prey. Protection in both is afforded by armour-plating, spines and barbed wire. In both evolution and warfare we find the use of chemicals, which is practiced by certain insects and by crea- tures such as the skunk. [8]

Boyd, a prominent military theorist, suggested that similar to biological evolution war os- cillates on a continuum that cannot be broken into discrete points or steps in time. Therefore both soldiers and ecologists try to find a mechanism that matches the crude reality of life. He pointed out that the theory of evolution by natural selection and the conduct of war are inti- 
mately related since both "treat conflict, survival, and conquest in a very fundamental way" He regarded war as a conflict between two self-organising, living and fluid-like organisms consisting of many mutually interacting and coevolving parts that form a rich interlacing tapestry of emergent possibilities. [9]

\section{Emergence and Self-Organisation}

At the heart of biological evolution there are two interrelated mechanisms such as emergence and self-organisation that require a closer examination. Emergence indicates bottom-up pro- cesses that cannot be predicted or anticipated in their fullness beforehand as they display features not previously observed. It is a holistic configuration that offers explanation into the dynamics of the system rather than explanation based on the system's parts alone. Thus emer- gence does not allow for predictions based on deduction and causality. It is not a provisional construct either, since its temporal and spatial aspects point toward greater and greater unpre- dictability. Emergence does not allow exact prediction of future states and cannot be handled by analytical rationality. It produces unexpected or counterintuitive results, which indicates that causes and effects are not only separate, but often disconnected or indirectly related in space and time. Emergence reflects attributes such as compensation and counteraction, which make most attempts to predict and plan for desired outcomes impossible, as such properties cannot be added together in a simple and system-wide way. [10]

Similar to biological evolution, in the case of military operations, despite the centralized design of military organisations, structures can also come from self-organisation on various levels. There is an abundance of spontaneous adjustments in military operations that involve complex interactions of so many factors that control becomes impossible. Self-organisation means that a species and military organisations involved in operations adjust to changes dy- namically even if those changes appear in an irregular fashion. Although self-organisation happens at all levels, the components operate on local information and general principles that have only limited content for the system as a whole. For the operational planning process of the military as outlined in official NATO publications self-organisation indicates a clear limitation as "causes and effects cannot be mapped linearly; similar causes can have different effects and different causes similar effects; small changes of causes can have large effects, whereas large changes can also result in only small effects (but, nonetheless, it can also be the case that small causes have small effects and large causes large effects)." [11]

\section{Environment Does Matter}

The dual processes of emergence and self-organisation point toward the fact that in open and dissipative systems such as biological evolution and military operations the living envi- ronment must also be taken into account. The environment is never static, but changes over time, which indicates that interactions stand more for what we do not know, and less so for the possibility to make accurate predictions regarding the system's future state. In order to get a better insight into the causal texture of the environment Emery suggested a simple matrix as depicted below. According to this matrix emergence arises as the interplay of L11 that refers to the processes found within the system, L12 and L21 both referring to interactions between the system and the environment, and L22 referring to processes and interaction within the 
environment itself. The matrix indicates that the environmental interdependences of complex phenomena such as biological evolution and military operations are often incommensurate with those connecting parts of the system. In other words, the environment is not just out there, but constantly changes in ways no one can anticipate: [12]

\section{L11, L12}

$\mathrm{L} 21, \mathrm{~L} 22$

Environmental factors also indicate that emergence and self-organisation stand for two sorts of unpredictability. Whereas in spatial or organisational terms they stand for the fact that properties at a certain level cannot be predicted from properties of other levels, in temporal terms they indicate unpredictability coming from the properties that constitute the preceding condition. Consequently, they create new properties regardless of the substance involved since they relate levels to each other by often denoting the very passage that connects them. Biological evolution and military operations are complex phenomena in which several levels co-exist simultaneously and interpretations based on cause-and-effect relationships often lead to mistakes. This poses a challenge to the traditional operational planning process of the military since it refers to something that disrupts the notion of causal explanation and cracks its power. The environment in which both biological evolution and military operations happen, stands for a qualitative change suggesting that causality and randomness are always interwoven in an intriguing and contingent way. Both display novelty in the form of new and random solution paths open to chance occurrences that do not allow for simple explanations. Although biological evolution and military operations might allow for the prediction of cer- tain structural features in general terms, as complex phenomena they do not help predict details of their future in terms of desired outcomes. [13]

\section{Adaptation as Tinkering}

Comprehending war in an evolutionary framework rejects classical theories and promotes complexity thinking that requires a shift from mechanics to biology. The emphasis moves from statics to dynamics, from time-free to timeprone reality, from determinism to proba- bility and chance, and from uniformity to variation and diversity. [14]

However, it must also be stated that unlike in military operations adaptation in biological evolution is run in evolutionary time to build up equipment for races run in real time with a trick: for an individual gazelle it is more important to outrun the slowest gazelle than to outrun the hunting cheetah. Nevertheless adaptation is full of a heavy dose of futility that loads it down as an extremely complicated balance of compromises must be micromanaged. The optimum compromise in this trade-off is not fixed as everything is fleeting and depends on a vast array of factors. [15] In his book the Greatest Show on Earth evolutionary biologist Dawkins made it clear that much of biological evolution is about tinkering as adaptation is often followed by corrections to secondary problems caused by adaptation itself. Natural selection works as a sweeper-up of countless minor details that come along after a big original error occurred. Major design flaws may be corrected subsequently or go extinct with the organism, which can perfectly compensate for the initial error. Also major mutations, even if they cause improvements, almost always require some sort of subsequent tinkering. They are often followed by lots of 
small mutations that have the only function to smooth out the rough edges just created. In biological evolution there is a pattern of major design flaws, compensated for by subsequent tinkering. Initial mistakes are corrected in a post hoc fashion as improvements can only be achieved by making ad hoc modifications. In biological evolution there is a wide variety of cumbersome accretion of compensatory bodges and fixes, and kludges. Biological innova- tions sometimes evolve not from old organs doing the same job, but from organs that are completely different. [15]

Similar to biological evolution there is no way to separate obvious changes occurring during the course of military operations and treat them in isolation. There are hundreds and thousands of ramifications as the interaction with the adversary tweaks and alters constantly. Changes in biological evolution initiate a complicated cascade of consequences, each of which necessitates compensatory adjustments. Even if one is overwhelmingly impressed by the elegance of some evolutionary design, there is a haphazard mess inside. Biologist Pit- tendrigh regarded biological evolution to be nothing more than a "patchwork of makeshifts pieced together, as it were, from what was available when opportunity knocked, and accepted in the hindsight, not the foresight, of natural selection." [16]

\section{Tinkering in Military Operations}

Tinkering and make-shift modifications to approved plans are of little appeal to military or- ganisations. Yet they have to except tinkering as a form of adaptation if they want to prevail. In fact, military history is full of examples of tinkering this or that way. In his book Command in War military historian van Creveld writes that the Battle of Jena fought in 1806 is a good example for adaptation. Although Napoleon achieved one of his biggest victories he "had known nothing about the main action that took place on that day; had forgotten all about two of his corps; did not issue orders to a third, and possibly to a fourth; was taken by surprise by the action of a fifth; and, to cap it all, had one of his principal subordinates display the kind of disobedience that would have brought a lesser mortal before a firing squad." [17]

Napoleon, one of the greatest commanders of all time was not only able to tolerate a high degree of uncertainty and still exploit the situation, but also his subordinates were willing to accept responsibility and act on self-initiative. It appears that military operations in general require a large safety margin in order to ensure that mistakes do not accumulate and develop into disasters. Similar to the emergent and self-organising mechanisms of biological evolution, military operations also contain a lot of blunders and errors that require subsequent tinkering. This however, indicates that operational planning should often not go further than the first encounter with the enemy and the amount of information needed to act at any given level should be reduced to a minimum. [17]

Adaptation indicates that war requires only general statements to be stated in advance in order to start activities rather than a detailed plan. Thus only guidelines must be laid down in order to put the system into gear. As soon as interactions with the enemy gain momentum, details that cannot be anticipated beforehand will emerge anyway. Another good example for successful tinkering was the 1967 Arab-Israeli war in which for the Israeli side "only the first [day] was planned in any detail; the rest was pure improvisation." [17: 200]

Tinkering stands for creativity, constant change, evolving situations and limitations re- garding comprehension, prediction and control. In complex phenomena such as biological 
evolution and military operations much depends on chance as possibilities always emerge and form a broad spectrum. Adaptation demands flexibility, robustness, and the ability to exploit constantly shifting opportunities. Soldiers must embrace open strategic options with various paths and try to make the best of probabilistic occurrences within the domain of their focus. Successful adaptation in military operations means that it is sometimes better to let patterns emerge than impose an artificial consistency prematurely. A peripheral vision is required to detect and take advantage of unfolding opportunities and the ability to tinker consistently to the unpredictable nature of military operations. Tinkering makes it possible to handle several different futures and stands in sharp contrast with mechanical, deductive systemic analyses aimed at detecting causality. [18]

\section{Conclusion}

Adaptation in military operations requires that soldiers evolve rapidly to handle dynamic and changing situations instead of focusing on anticipated circumstances and conditions that come as a result of single and rigid prescriptive models. Biological evolution as a basis for better understanding the dynamics of military operations certainly does good service. It helps value the many irregular processes found on the tactical level, and can find a balance between centralization and decentralization in military organisations. It can also facilitate a better un- derstanding for achieving a match between the external diversity of the environment and the internal variation of military organisations in order to help soldiers cope with the many chal- lenges present in that environment. Among others studying biological evolution can also help find a good fit between a required minimum of regularity in the form of top-down guidance and a maximum of tolerable irregularity coming from bottom-up as information.

British military theorist Liddel Hart, who cannot be regarded as a biologist at all, pointed out in a nearly perfect biological language the essence of this approach. According to him "instead of fusing individuals into a mass through the suppression of their individuality and the contraction of their thought, the lead ... only has effect, lightning effect, in proportion to the elevation of individuality and the expansion of thought. For collective action it suffices if the mass can be managed; collective growth is only possible through the freedom and en- largement of individual minds. It is not the man, still less the mass, that count; but the many." [19: 356]

Regarding cause-and-effect relationships in war he also pointed out that "bad means deform the end, or deflect the course thither" and concluded that the only thing left possible is to acknowledge that in complex situations such as military operations "if we take care of the means the end will take care of itself." [19: 357] In a similar fashion also Helmuth von Moltke emphasised that "[i]n war it is often less important what one does than how one does it." [20: 33]

Then, shall we start with biology? 


\section{References}

[1] GOLDSTEIN, J.: Emergence as a Construct: History and Issues. Emergence, 1 (1999), 49-72. https://doi.org/10.1207/s15327000em0101_4

[2] LEVIN, S. A.: Ecosystems and the Biosphere as Complex Adaptive Systems. Ecosystems, 1 (1998), 431-436.

[3] OVINGTON, C. O.: War and Evolution. The Westminster Review, April (1900), 411-420.

[4] COLE, L. J.: Biological Philosophy and the War. The Scientific Monthly, 3 (1919), 247-257. [5] CLAUSEWITZ, C. v.:

War.PAninceton University Press, 1989.

[6] WATTS, B. D.: Clausewitzian Friction and Future War. National Defence University, 2004.

[7] Quot. in DARWIN, C. R.: On the Origin of Species, By Means of Natural Selection, Or the Preservation of Favoured Races in the Struggle for Life. MURRAY, J. 1859, 73., 80., 490.; DARWIN, C. R.: The Descent of Man, And Selection in Relation to Sex. MURRAY, J. 1871.

[8] COTT, H. B.: Adaptive Coloration in Animals. Methuen \& Co. Ltd., 1957. [9] Quot. in BOYD, J.:

Patterns of Conflict. Manuscript, 12 (1986), 11.

[10] GOLDSTEIN, J.: Emergence as a Construct: History and Issues. Emergence, 1 (1999),

49-72.; STACEY, R. D.: Strategic Management \& Organisational Dynamics. Pitman Publishing, 1996.; AXELROD, R., COHEN, M. D.: Harnessing Complexity, Organizational Implications of a Scientific Frontier. The Free Press, 1999.;

COHEN, J. E.: The Counterintuitive of Cooperation of Conflict. Scientific American, 11-12 (1988), 577-584.

[11] AJP-5 Allied Joint Doctrine for Operational Planning. NATO NSA, Ratification Draft, 2006.; CILLIERS, P.: Complexity and Postmodernism, Understanding Complex Systems.

Routledge, 1998.; KROHN, W., KÜPPERS, G.: Self-organization: A new approach to evolutionary epistemology. In. HAHLWEG, K., HOOKER, C. A. (Eds.), Issues in Evolutionary Epistemology. State University of New York Press, 1989.; Quot. in FUCHS, C.: Structuration Theory and Self-Organization. Systemic Practice and Action Research, 2 (2003), 135.

[12] MOFFAT, J.: Complexity Theory and Network Centric Warfare. Information Age Transformation Series, CCRP Publication Series, 09 2003.; EMERY, F. E., TRIST, E. L.: The Causal Texture of Organizational Environments. Human Relations, 18 (1965), 21-32.; GREEN, D. G., NEWTH, D.: Towards a theory of everything? - Grand challenges in complexity and informatics. Complexity International, 8 (2001), 1.; JERVIS, R.: Complex Systems: The Role of Interactions. In. ALBERTS, D. S., CZERWINSKI T. J. (Eds.), Complexity, Global Politics and National Security. National Defence University, 1997.

[13] EMMECHIE, C., KØPPE, S., STJERNFELT, F.: Explaining Emergence: Towards an Ontology of Levels. Journal for General Philosophy of Science, 28 (1998), 83-100.; GOLDSTEIN, J.: Causality and Emergence in Chaos and Complexity Theories. In. SULIS, W., COMBS, A. (Eds.), Nonlinear Dynamics in Human Behaviour, World Scientific, 1996.; SCOTTI, M., CIOCCHETTA, F., JORDÁN F.: Social and landscape effects on food webs: a multi-level network simulation model. Journal of Complex Networks, 1 (2013), 1-23.

[14] MODELSKI, G., POZNANSKI, K.: Evolutionary Paradigms in the Social Sciences. International Studies Quarterly, 40 (1996), 315-319.; ANDRESKI, S.: Evolution and War. Science Journal, January (1971), 89-92.

[15] DAWKINS, R.: The Greatest Show on Earth. Free Press, 2009. 
JOBBÁGY Zoltán: On Adaptation in Military Operations: Tinkering and Bottom-Up Perspectives

[16] DAWKINS (2009.); PITTENDRIGH, C. S.: Adaptation, natural selection, and behavior. In. ROE, A., SIMPSON, G. G. (Eds.), Behavior and Evolution, Yale University Press, 1958.

[17] CREVELD, M. van: Command in War. Harvard University Press, 1985.

[18] QUINN, J. B.: Strategy, Science and Management. MIT Sloan Management Review. Summer (2002), 96-105.; DENT, E. B.: Complexity Science: a Worldview Shift. Emergence, 4 (1999), 5-19.; WILLIAMSON, P. J.: Strategy as Options on the Future. MIT Sloan Management Review, spring (1999), 117 126.; LUEHRMAN, T. A.: Strategy as Portfolio of Real Options. Harvard Business Review, 09-10 (1998), 8999.; GEUS, A. P. de: Planning and Learning, At Shell planning means changing minds, not making plans. Harvard Business Review, 03-04 (1988), 70-74.; FELD, M. D.: Information and Authority: The Structure of Military Organization. American Sociological Review, XXIV (1959), 15-

22.; BEINHOCKER, E. D.: Robust Adaptive Strategies. MIT Sloan Management Review. Spring (1999), 95-106.; Quot. in CHILCOAT, R. A.: Strategic Art: The New Discipline for 21st Century Leader. In. CERAMI, J. R., HOLCOMB, J. F. (Eds.), U.S. Army War College Guide to Strategy, U.S. Army War College, 2001. 207.; PASCALE, R. T.: Surfing the Edge of Chaos. MIT Sloan Management Review, spring (2003), 83-94.

[19] Quot. in LIDDEL HART, B. H.: Through the Fog of War, Faber and Faber Ltd., 1938.

[20] Quot. in HOWARD, M.: The Influence of Clausewitz. In. CLAUSEWITZ, C. v.: On War, Princeton University Press, 1989. 